\title{
Initial data from monitoring of a landslide process affecting Emine Cape, Bulgaria
}

\section{Първоначални данни от мониторинг на свлачищен процес, засягащ нос Емине, България}

\author{
Nikolai Dobrev, Plamen Ivanov, Miroslav Krastanov, Antoaneta Frantzova \\ Николай Добрев, Пламен Иванов, Мирослав Кръстанов, Антоанета Францова
}

Geological Institute, Bulgarian Academy of Sciences, Acad. Georgi Bonchev Str., Bl. 24, 1113 Sofia;

E-mails: ndd@geology.bas.bg; plivanov62@geology.bas.bg; miro_k@geology.bas.bg; afrantzova@gmail.com

\begin{abstract}
In October 2019, a 3D extensometer was installed to monitor slow landslide movements, affecting the slope of Cape Emine north of the lighthouse. For almost 2 years of observations, a tendency of shrinkage of the zone as a result of lateral pressure from the southern landslide was established. The movements are divided into two stages: the first - until December 2020, and the second - after that date. In the months from April to June the movements in direction $\mathrm{X}$ are more intensive due to the rainy situation at this time of the year.
\end{abstract}

Keywords: landslides, monitoring, flysch, Emine Cape.

\section{Въведение}

В края на 2014 г. се появи информация в различни медии относно „разцепване на земята на нос Емине“ и „превръщането му в остров“ (https:// www.flagman.bg/article/73514, и др.). През следващите години информацията се потвърди от местни източници, че се появило „хльтване“ на пътя между портала и фара с около $40 \mathrm{~cm}$ през зимния период след интензивни валежи. Рязкото движение вероятно се е случило през декември 2014 г. По данни от МРРБ и Националния статистически институт (https://www.nsi.bg/bg/ content/свлачища) в периода от декември 2014 г. до средата на април 2015 г. са регистрирани 103 свлачища в Националния свлачищен регистьр. Те се активизират след редуващи се периоди на продължителни валежи (дъжд или сняг) и интензивно снеготопене.

Това даде идея за провеждане на изследване на района, което бе осъществено през 2019 г. В резултат бе установено наличие на свлачищни процеси в около 100-метров участьк по склона северно от фара. През октомври 2019 г. бе инсталиран екстензометър ТМ-71 на единственото удобно място, където има ясно очертана пукнатина и е възможно провеждането на инструментални наблюдения върху динамиката на свлачищните процеси.

\section{Геоложки строеж}

Геоложкият строеж в района на нос Емине е еднообразен - представен е единствено от Еминската флишка формация $\left(\mathrm{emK}_{1}^{\mathrm{cp}}-\mathrm{Pg}_{1}\right)(\mathrm{Kanchev}$, 1995). Свитата е изградена от редуващи се мергели, глини, варовити мергели и пясъчници. Дебелината на пластовете варира от 1-2 до 30-40 cm. Възрастта на свитата е спорна - според различните изследователи тя варира от Късна Креда (Кампан) до Палеоцен (Дан) (Botev, 1953; Boshev et al., 1967; Karagjuleva, Kostadinov, 1977; Juranov, Pimpirev, 1989; Sinnyovsky, Stoykova, 1995 и др.). Общата дебелина на Еминската свита се оценява на 1500-2000 m.

Мястото, където са установени свлачищните процеси, има следните характеристики:

- Пластовете са с посока 95-105 и наклон $33-36^{\circ}$ на изток. Склонът е стръмен, като в долната част при прибоя надхвърля 60-65 . 
- В горната част на склона са установени свлачищни циркуси, които на места имат заличени форми. Установяват се няколко генерации свличания - налице са частични припокривания на различните циркуси един върху друг. Съгласно геоморфоложките белези, по-активна е най-южната част (откъм фара), където е оформено свлачище с площ около $4000 \mathrm{~m}^{2}$. Това дава основание да предполагаме, че то е по-активно.

- Второто свлачище е разположено от левия борд на гореспоменатото. Приблизителната му площ е около $5200 \mathrm{~m}^{2}$. При него се наблюдават наслагвания на няколко стари свличания с различен обхват. На този етап е трудно да се направи детайлно картографиране и на двете свлачища поради труднодостьпния терен и липсата на подходяща техника.

Проявените свличания са от транслационен тип съгласно класификацията на Varnes (1978). Движенията се осъществяват по по-слабоспоените глинесто-мергелни прослойки сред флиша. Дълбочината на свлачището не е точно установена. По предварителна експертна оценка тя най-вероятно е около 3-5 m, съдейки по деформациите по склона в северната част, също и по геофизичните проучвания. Последните, проведени през 2020 г., показаха, че най-вероятно тя е не повече от $5 \mathrm{~m}$.

\section{Апаратура}

За установяване на реалните стойности на движения е използван механо-оптичният апарат (3D екстензометър) ТМ-71, чешко производство (Kostak, 1991). Екстензометърът е пригоден за постоянно следене на бавни движения, които трудно биха могли да бъдат уловени с използване на регулярни средства за наблюдение. Наблюденията се извършват на място, директно на избраната позиция на даден разлом или свлачищна пукнатина, като се отчитат преместванията и по трите пространствени оси X, Y и Z. Измерителният му обхват е $25 \mathrm{~mm}$. Преместванията по трите координатни оси се изчисляват чрез тригонометрични формули. Регистрацията на преместванията се извършва на равни интервали от време, в зависимост от динамиката на наблюдавания процес. Тъй като дневните и сезонните температурни колебания оказват влияние върху показанията на прибора (особено по осите, съвпадащи с направленията на конзолите), се прави температурна корекция на измерените премествания. Приборът има широко приложение в практиката: използва се за контрол на движения и деформации както в блоков тип свлачища и активни разломи, така и в строителството, при опазването на исторически и архитектурни паметници и др. (Frangov et al., 1992 и др.).

Апаратьт бе инсталиран на 22.10.2021 г. Избраното място е в нарушена зона, широка 0,50,6 m, намираща се на границата между двата свлачищни участька. Локалната посоката на пукнатината е $18^{\circ}$, а посоката на конзолите е съответно перпендикулярна $-108^{\circ}$. Значенията на пространствените оси са следните: +X - свиване (компресия) на зоната; +Y - дясно движение (или северното свлачище надолу по склона); +Z - потьване на северното свлачище (респ. издигане на южното свлачище).

Наблюдателната точка е с № 12 по единна номерация в страната.

\section{Резултати}

Обработени са данните от 32 записа от екстензометъра ТМ-71, направени в периода 22.10.2019 г. -11.10.2021 г. Резултатите са представени в графичен и табличен вид (фиг. 1, табл. 1). Първоначалният анализ на графиките на преместванията показва, че може да се отделят два етапа в движенията: първи, от началото на измерванията до 16.12.2020 г.; втори, от същата дата до октомври 2021 г.

Забелязва се увеличаване на скоростта на свиване на пукнатината (oc X) между месеците април и юни, която е характерна и за двете години - 2020 и 2021 г. Това се обяснява с валежната обстановка по време на този период от годината. За отбелязване е също и високият коефициент на детерминация, особено за направления X и Z.

\section{Заключение}

Първоначалните данни показват високи стойности на наблюдаваните движения. Те са най-силно изразени по ос $\mathrm{X}$, както и по ос $\mathrm{Z}$ през втория етап (след декември 2020 г.). Всички те ясно показват, че по-активно е южното свлачище (до фара), което притиска северното откъм левия си борд.

Основни дестабилизиращи фактори са валежите и вероятно абразията. Тъй като свлачищата не са добре изучени в долните си части, засега трудно може да се определи делът на абразионния фактор. Със сигурност обаче той е значим при щормови проявления в прибойната част в основата на свлачищата.

Получените до този момент данни за свлачищните движения при нос Емине имат важно значение за определяне на тяхната динамика. За по-пълна представа обаче е необходимо разширяване на наблюденията чрез използване и на допълнителен мониторинг, например чрез геодезия, щифтови марки, лазерно сканиране и др. 


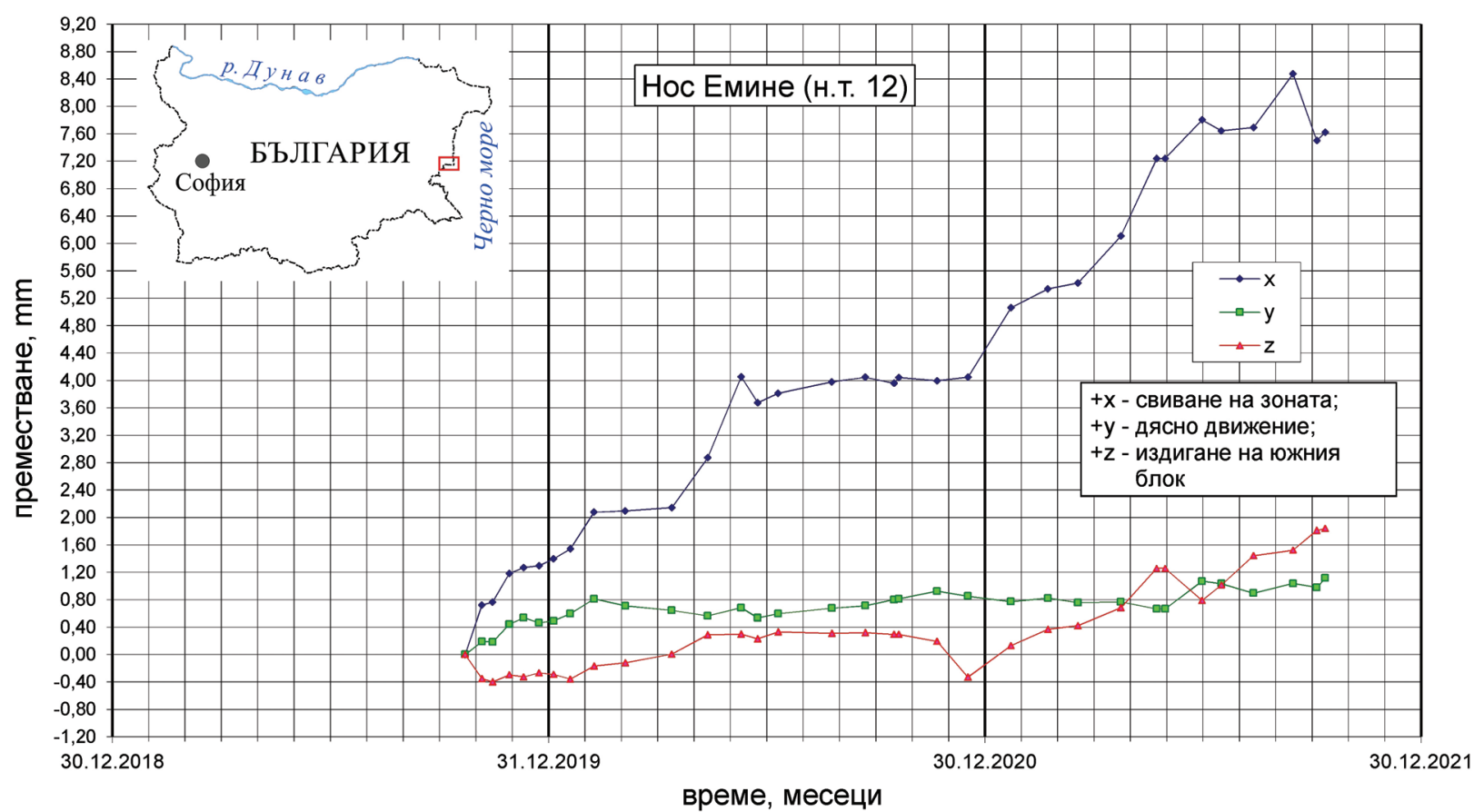

Фиг. 1. Графика на установените премествания в наблюдателна точка № 12

Таблииа 1. Установени годишни скорости на движения през двата етапа на наблюдение при точка № 12 и съответния коефициент на детерминация $r^{2}$

\begin{tabular}{lccc}
\hline \multicolumn{1}{c}{ Направление } & $\mathrm{X}$ & $\mathrm{Y}$ & $\mathrm{Z}$ \\
Период & & & \\
\hline \multirow{2}{*}{$22.10 .2019-16.12 .2020$} & $3,50 \mathrm{~mm} / \mathrm{a}$ & $0,48 \mathrm{~mm} / \mathrm{a}$ & $0,51 \mathrm{~mm} / \mathrm{a}$ \\
& $\mathrm{r}^{2}=0,91$ & $\mathrm{r}^{2}=0,62$ & $\mathrm{r}^{2}=0,46$ \\
\multirow{2}{*}{$16.12 .2020-11.10 .2021$} & $4,68 \mathrm{~mm} / \mathrm{a}$ & $0,36 \mathrm{~mm} / \mathrm{a}$ & $2,38 \mathrm{~mm} / \mathrm{a}$ \\
& $\mathrm{r}^{2}=0,87$ & $\mathrm{r}^{2}=0,48$ & $\mathrm{r}^{2}=0,93$ \\
\hline
\end{tabular}

Благодарности: Настоящото изследване бе проведено при изпълнение на проект „Национален геоинформационен център“ (НГИЦ), финансиран по договор Д01-404/18.12.2020 г. с Министерството на образованието и науката, Република България.

\section{Литература References}

Boshev, S., B. Strashimirov, S. Zafirov, R. Hristov, M. Moev. 1967. Geology of the coastal part of the Eastern Stara Planina. - Ann. Mining and Geol. Inst., 12, 2-Geol., 7-62 (in Bulgarian with English abstract).

Botev, B. 1953. Notes on the geology of the easternmost part of the Eastern Stara Planina. - Bull. Geol. Inst., 2, 3-20 (in Bulgarian with English abstract)

Frangov, G., P. Ivanov, N. Dobrev, I. Iliev. 1992. Stability problems of the rock monument "Madara horseman". - In: Proc. 7th Int. Congr. Deterioration and Conservation of Stone. Lisboa, Portugal, 1425-1435.
Juranov, S., H. Pimpirev. 1989. Lithostratigraphy of the Upper Cretaceous and the Paleogene in the coastal part of East Stara Planina. - Rev. Bulg. Geol. Soc., 50, 2, 1-18 (in Bulgarian with English abstract).

Kanchev, I. 1995. Explanatory Note to the Geological Map of the Republic of Bulgaria. Scale 1: 100 000. Map Sheet Dolni Chiflik. Geology and Mineral Resources Committee, Enterprise of Geophysical Survey and Geological Mapping, Sofia, $113 \mathrm{p}$.

Karagjuleva, J., V. Kostadinov. 1977. Geological structure of the eastern part of the Luda Kamchia zone. - Geotect., Tectonophys., Geodinam., 7, 42-75 (in Bulgarian with English abstract).

Kostak, B. 1991. Combined indicator using moiré technique. In: Proc. 3rd Symp. Field Measurements in Geomechanics. Oslo, 53-60.

Sinnyovsky, D., K. Stoykova. 1995. Cretaceous/Tertiary boundary in the Emine Flysch Formation, East Balkan, Bulgaria: Nannofossil evidence. - C. R. Acad. bulg. Sci., 48, 3, 45-48.

Varnes, D. J. 1978. Slope movement types and processes. - In: Schuster, R. L., R. J. Krizek (Eds.). Landslides, Analysis and Control. Special Report 176. Washington, 11-33. 